\title{
o mercado colonial: a construção de um espaço interno
}

\author{
Cláudia Maria das Graças Chaves \\ Professora da Universidade Federal de Viçosa
}

\section{RESUMO}

Este artigo analisa a produção historiográfica sobre o mercado interno na América Portuguesa. Discute as implicações da utilização do conceito de um espaço colonial fragmentado, o qual somente no final do século XVIII passou a possuir um projeto de integração dentro do Império Luso-Brasileiro.

Palavras-chave: mercado interno, territóno colonial, Império Luso-brasileiro.

\begin{abstract}
This article analyses the historiographic production on the internal market in Portuguese America. It discusses the implications of the use of this concept within a fragmented colonial space, that only at the end of the 18 th century began to possess an integration project in the Luso-Brazihan Empire.
\end{abstract}

Key words: internal market, colonial territory, Luso-Brazilian Empire.

Estudar o mercado interno colonial brasileiro exige, sem dúvida, uma análise conceituai mais ampla, e que implica a priori na definição da palavra mercado e da relação estabelecida com a criação de um espaço econômico e territorial. Embora não pareça ser um verdadeiro problema para a historiografia, a menção da expressão "mercado interno" relacionada à economia colonial, quase sempre vem acompanhada de adjetivos que enfatizam a sua especificidade, o que, por sua vez, demonstra suas restrições. As palavras "secundário","ancilar" e "subsidiário", entre outras, caracterizaram a existência de um mercado interno na Colônia, ou das produções destinadas ao abastecimento interno, segundo a historiografia clássica ${ }^{2}$, pelo menos, até a

Uma primeira versão deste artigo foi apresentada no I Encontro de Pós-Graduação em História Econômica em Araraquara 09/2002, promovido pela ABPHE.

Ver: Prado Jr. (1978); Sinionsen (1957); Furtado (1974). 
década de 1970. Tratava-se, naquele período, de compreender o Brasil dentro de um sistema econômico mundial em que não havia espaço para autonomias coloniais.

Quando esse modo de percepção passou a ser questionado pela historiografia brasileira, as formas de produção internas voltadas para o comércio intracolonial tornaram-se relevantes. A Colônia já não era vista como simples reflexo da metrópole, e tinha capacidade de gerar riquezas e alternativas à economia agroexportadora vinculada à economia metropolitana ${ }^{3}$. Ou seja, as produções voltadas para o "mercado interno" tornavam-se uma importante fonte de renda para os seus produtores. Os estudos realizados entre as décadas de 1970 e 1980 valorizaram os aspectos internos da economia colonial da A mérica Portuguesa com ênfase na esfera da produção. A "agricultura mercantil de subsistência" ganhou destaque ao lado da reavaliação do trabalho escravo e de base familiar. Não se tratava mais de um excedente agrícola comercializável, mas de uma produção voltada para o mercado interno.

Entretanto, não se podia deixar de lado o fato de ser a economia brasileira ainda anterior a 1822 uma economia colonial. Essa economia era baseada no emprego do trabalho escravo e no trabalho livre não-assalariado, na agroexportação, na inexistência ou insuficiência de moedas e das diferenciadas formas de crédito, na distribuição latifundiária das terras, além de estar submetida ao rígido controle político e burocrático do Estado português. Isso tudo, é claro, implicaria no redimensionamento das questões teórico-metodológicas. Tratava-se de analisar um sistema econômico com sua própria dinâmica, e que não se enquadrava nos modelos clássicos do "capitalismo comercial".

A definição do modo de produção escravista-colonial elaborada ao longo da década de 1970, também não era, por sua vez, suficiente para explicar a economia colonial, seja porque não era possível definir um sistema econômico a partir da escravidão, seja por que as "leis" desse modo de produção restringiam os campos de análise da estrutura colonial e esterilizavam o debate. Durante a década de 1980 , essa questão perdeu o vigor já que novas temáticas se tornavam mais

Ver: Cardoso (1979); Linhares (1979); Linhares \& Silva (1981); Schwartz (1976).

Fragoso discute aqui os modelos explicativos de um modo de produção escravista colonial propostas por Cardoso (1979) e Gorender (1978). 
atrativas e menos árduas nos campos da análise social e cultural e buscavam compreender a complexidade da sociedade colonial a partir de novos parâmetros.

Embora a questão do mercado interno não tenha desaparecido dos estudos históricos, ela deixou de suscitar mais debates conceituais, tornando-se aceitas a sua existência e sua importância na definição do mundo colonial. Mas, no início da década de 1990, o trabalho de João Fragoso (1992) forçou novamente a busca por uma definição conceituai da economia colonial, e o seu livro, Homens de Grossa Aventura: Acumulação e Hierarquia na Praça Mercantil do Rio de Janeiro (1790-1830), tornou-se uma obra de referência nos últimos anos. Segundo Fragoso, o escravismo colonial em sua reprodução "gera formas de produção não-capitalistas, ligadas ao seu abastecimento" (1992:27). São elas o trabalho camponês, livre e não-assalariado, e o trabalho escravo na produção de alimentos. Esse processo, de acordo com o Autor, "introduz (ou redimensiona) três categorias da economia colonial"(Fragoso, 1992:27): acumulação endógena, mercado interno e capital mercantil colonial residente.

Apesar dessas três categorias estarem interligadas, quero enfatizar aqui o mercado interno. Para Fragoso, esse mercado tem todas as características de uma economia não-capitalista - isto é, ele possui uma frágil divisão social de trabalho (predominantemente escravismo e campesinato) e uma frágil circulação de moedas e mercadorias. Essas características dariam, portanto, um caráter restrito e imperfeito para esse mercado. Dessa maneira, o conceito de mercado utilizado é dado pelos parâmetros do sistema capitalista. Embora a caracterização esteja correta, penso que tais adjetivos sejam desnecessários, pois o próprio Autor, ao construir um quadro explicativo para a economia escravista-colonial, define, entre os elementos estruturais dessa economia, os traços marcantes do sistema econômico-social implementado pela Metrópole no Antigo Regi me.

Tais traços, segundo Fragoso, permitiram, no Brasil, a presença de um mercado interno com acumulações endógenas e uma comunidade mercantil residente, embora condicionados pelo Estado metropolitano contrário ao fortalecimento de grupos sociais e a acumulações que resultassem numa modernização capitalista (Fragoso, 1992:307). Dessa maneira, o Autor demonstra a insuficiência dos modelos explicativos da economia colonial que propõem, como sendo o objetivo daquela sociedade, a reprodução de suas 
estruturas internas contínuas no tempo. Com isso, tornava-se a economia colonial incompatível com a existência de um mercado interno de peso.

A partir dessa discussão historiográfica, vejamos algumas questões propostas para repensarmos o mercado colonial e a construção de um espaço econômico interno sem, contudo, restringi-lo do ponto de vista conceituai - isto é, sem tomarmos como parâmetro ou pressuposto os "mercados perfeitos". Quase sempre, quando se fala em mercado interno no período colonial do Brasil, fala-se em século XVIII. Será que esse mercado surge a partir do Setecentos? O que existia antes? Uma economia de subsistência sem trocas comerciais ou uma economia natural?

Trabalhos relativamente recentes como o de Jacob Gorender (1990) que salientou "o enfoque de dentro para fora" da dinâmica interna da produção colonial, o mercado interno continuou sendo um fator secundário.

"No escravismo colonial, o mercado interno funcionava como suporte da produção para exportação. Tinha caráter subsidiário, secundário; mesmo quando envolvia um grande número de pessoas. Mas um historiador que se ocupa de um aspecto secundário não é, só por isto, um historiador 'secundário'. Não precisa supervalorizar o seu tema para ganhar status". (1990:81)

Neste seu estudo, Gorender até ressalta a existência do mercado interno, ainda que subsidiário. Em seu mais famoso estudo, $O$ Escravismo Colonial, ele classificou a economia colonial de economia natural, dado que se tratava de economia altamente especializada, e que as condições para a reprodução do modo de produção escravista correspondiam às de produções para o auto-sustento dentro dos engenhos de cana-de-açúcar.

Quando as análises historiográficas passaram a ressaltar não só a existência de um mercado interno, como também a sua grande importância para uma relativa autonomia econômica da Colônia, a ênfase recaía sobre as produções voltadas para o mercado no século XVIII, na região centro-sul. A explicação mais recorrente para essa periodização tem sido explícita ou implicitamente dada em função de se haver constituído, no século XVIII, um maior adensamento populacional. Assim, a formação de núcleos urbanos mais expressivos culminou com a abertura de estradas e a criação de tropas muares, 
possibilitando o desenvolvimento de redes de abastecimento, sobretudo na região centro-sul.

Analisando a historiografia brasileira, sobretudo os aspectos econômicos, Jorge Caldeira considerou o mercado interno brasileiro do século XVIII como uma revolução na economia colonial. Em torno dos pontos de comercialização abertos pelos tropeiros, foi-se constituindo, segundo o autor, uma rede nacional de distribuição, abrindo espaço para uma economia de mercado: "Economia de mercado ao alcance de qualquer um" (Caldeira: 1999:189). Sempre às voltas com conceitos específicos da economia capitalista, Caldeira vê a mineração como o início da montagem de uma rede de comércio no Brasil. Ela traria flexibilidade às trocas monetárias, uma vez que o ouro é também uma moeda, além de dar regularidade à atividade comercial.

"Em meio século as várias regiões mineradoras definiram, por uma seqüência imensa de agentes orientados pela lógica do mercado, os traços gerais de um mercado interno agora visível como tal, cujos principais produtos eram escravos, farinha e gado. Os mesmos produtos desenvolvidos no século anterior, porém com uma importante diferença: já não eram mais obtidos através de escambo ou redes de clientelismo, mas distribuídos por uma vasta rede de comerciantes. Os mesmos agentes do século anterior, mas agora visivelmente inteligíveis como tendo suas ações movidas pela lógica do lucro. Lucro que não se obtém apenas pelo comércio, mas pela montagem de empreendimentos tão regulares quanto possível, que devem apresentar ganhos ao final do processo de trabalho - seja por uma roça, hospedaria, venda de beira de estrada ou empresa de comércio sobre muares". (Caldeira, 1999:195)

A mineração e a interiorização criaram, assim, a oportunidade e a necessidade de se estabelecerem as redes de comércio. Não mais atividades de subsistência, não mais meros seguimentos das atividades agroexportadoras, definidas pelo tradicionalismo e pelo clientelismo. Agora tratava-se de atividades movidas pela lógica do lucro, pela lógica do mercado. Então essa é a verdadeira revolução do século XVIII ou o "milagre da natureza", que transforma a economia colonial. A atividade secundária torna-se atividade primordial. O que aconteceu para que homens que viviam frugalmente em suas trocas habituais se lançassem ferozmente para uma "economia de mercado"? Sobre o ouro, dirá esse autor: 
"O ouro não seria apenas o metal que brilhava nas minas, mas o agente detonador de um conjunto de atividades cuja lógica econômica era exatamente aquela que conhecemos atualmente: trabalhar para enriquecer, empreender em função da rentabilidade do negócio". (Caldeira, 1999:186)

Pela definição de mercado, e ao entendê-lo como trocas contínuas ou mesmo eventuais, deixa de ser problemático utilizarmos a palavra mercado para as trocas comerciais realizadas desde o início do processo de colonização no Brasil, entre pequenos agricultores e donos de engenhos. A produção de alimentos para mercados locais era um desdobramento da produção destinada ao consumo da unidade produtiva. Esses mercados locais eram isolados e não regulamentados, exceto para a comercialização em Vilas e arraiais próximos, para a qual havia posturas estabelecidas pelas Câmaras. Nesses mercados, havia um pequeno número de fornecedores para um pequeno número de compradores. A acumulação mercantil só se tornava viável através do mercado externo, com a produção e a comercialização - inclusive com a fixação de pontos comerciais - voltadas para o mercado local sendo pouco atrativas para incentivar uma especialização.

Seriam exatamente o maior adensamento populacional, o processo de urbanização e a interiorização que iriam estimular a criação de redes mercantis de abastecimento interno e de produção, não só alimentícia, para atender esse mercado que podemos chamar de interno. Polányi (2000:80-1) distingue os mercados locais dos mercados internos. Para ele, os primeiros são limitados em termos de oferta de mercadorias, das quais não compensa, por serem volumosas ou perecíveis, fazer o transporte a longas distâncias. A esse comércio, ele dá o nome de "complementar". Totalmente diferente é o mercado interno, também chamado de nacional, que é competitivo por oferecer um volume maior de mercadorias, de diferentes regiões, forçando uma integração territorial. Esse comércio interno foi, deste modo, um instrumento de "nacionalização" (Polányi, 2000:86).

No final do século XVIII, um dicionário de comércio e economia portuguesas incluía no comércio interno todo o Reino e os domínios ultramarinos, que só "per acidens" estavam tão distantes. Em 1811, a "Junta do Comércio, Agricultura, Fábricas e Navegação do Estado do Brasil e Domínios Ultramarinos", ao emitir um parecer sobre a

Arte e Dicionário ..., 1784. p 31-4. 
representação do Juiz de Alfândega, confirma que são consideradas como "nacionais" todas as manufaturas produzidas tanto em Portugal quanto no Brasil ${ }^{6}$ e, portanto, pertencente ao seu comércio interno. Produção e comercialização internas eram, portanto, consideradas elementos de nacionalização. Isso requer, sem dúvida, aquilo que Alencastro (2000:28) chamou de "idéia de filiação a uma comunidade supra-regional". Isto é, durante o período colonial, precisamos redimensionar nosso conceito espacial e territorial, principalmente para não nos esquecermos do império ultramarino.

Não pretendo estabelecer uma tipologia de mercados, entre mercados locais, internos e nacionais. Mas acho necessário compreender o sentido de mercado interno que se está utilizando. Trata-se apenas da designação de toda a produção e comercialização no interior do território brasileiro, ou inclui-se nela a integração de regiões e de comunidades através de trocas regulares e a criação de redes de comunicação constantes.

No caso do Brasil, não se pode deixar de admitir que há uma mudança - em termos de volume, especialização e de integração regional e, principalmente, da capacidade de gerar acumulação de riquezas - no processo de produção e no comércio para o consumo interno a partir da segunda metade do século XVII. Como foi dito mais acima, a maior parte da nossa historiografia registra o nascimento do mercado interno, ou a sua visibilidade, a partir do século XVIII, exatamente por representar o processo de trocas regulares no comércio interno e por representar a criação de redes de transportes e de casas comerciais fixas e, até mesmo, porque temos poucas abordagens para as atividades mercantis anteriores a esse período.

Em muitos dos trabalhos consultados, é dado o marco da mineração. Ela representou a criação de centros de abastecimento que impulsionavam a produção de alimentos para ricos mineradores. Atividades mais seguras e mais fáceis de se chegar ao ouro dirá Mafalda Zemella em seu estudo clássico e pioneiro sobre o abastecimento nas Minas (1990). Outros importantes estudos sobre abastecimento no Brasil colonial irão ressaltar o mercado consumidor formado nas zonas de mineração ${ }^{7}$, assim como também obras de síntese da História do

Fundo (7X) da Junta do Comércio, Agricultura, Fábricas e Navegação, cód. 46, v. 1, Biblioteca Nacional do Rio de Janeiro.

Ver: Ellis (1958); Goulart (1961); Holanda (1957 e 1977); Lenharo (1979); Linhares (1979) e Simonsen (1957). 
Brasil apontam para importância da mineração na consolidação de um mercado interno na colônia ${ }^{8}$. A produção de alimentos voltada para um mercado abastecedor coincide com o mesmo movimento da pecuária, que é "expulsa" para os "sertões" em fins do século $\mathrm{XVII}^{\circ}$, desvinculando a produção de alimentos e carnes para o abastecimento das plantations e de suas mediações.

José Jobson Arruda (1986) diz que a produção de subsistência era essencial à sobrevivência da Colônia e indispensável à condição de economia exportadora. Para isso, é necessário entendermos a economia colonial integrada ao sistema colonial, mas não como sinônimo, pois é necessário observarmos as especificidades, principalmente regionais, daquela. Pensando na região Centro-Sul, especialmente Minas Gerais, a partir do século XVIII, Arruda percebe uma economia de subsistência que não dependia do setor exportador. Já em regiões não perfeitamente integradas à produção dos produtos-chave da exportação, como era o caso do Pará, desenvolveu-se a produção de subsistência vinculada às grandes unidades produtoras e realizada por escravos. Conhecida por "brecha camponesa", essa forma de produção drenava seus excedentes para o mercado local. Entretanto, nas regiões mais dinâmicas, integradas ao comércio mundial, não se poderia generalizar o "esquema de produção de subsistência" (Arruda, 1986:125). Quanto ao mercado interno, Arruda diz que ele surge vinculado às atividades de comércio no interior da Colônia, o que pode ser percebido apenas a partir do século XVIII, devido à frágil integração entre as regiões coloniais. Assim ele distingue, mercado interno de simples produção para a subsistência. Para este Autor, três regiões internas se destacaram: Marinha, Minas e Sertão.

"Observada em conjunto, tal economia apresentava uma constelação de sistemas na qual alguns se articulavam entre si e outros permaneciam praticamente isolados. Os dois núcleos principais dessa articulação eram a economia açucareira e a mineira. Ao núcleo açucareiro, ligava-se a pecuária nordestina. Ao núcleo mineiro, ligava-se o interior pecuário do sul, que ia de São Paulo ao Rio Grande. Os dois núcleos principais ligavam-se frouxa-

Ver: Francisco Carlos Teixeira da Silva in: Linhares (1990) p. 60.

- Esta "expulsão" foi definida por alvarás que entre 1688 e 1700 expandiam as áreas de pecuária para fora das áreas de plantation. Cf. Linhares (1996) p. 112. 
mente através do rio São Francisco, por meio da pecuária nordestina que buscava a região das Minas. No Norte encontravam-se o Maranhão e o Pará como dois centros autônomos. (...). Recompondo, então, teríamos: a região açucareira, a região mineira e o Maranhão, interligando-se superficialmente através do interior pecuário". (Arruda, 1986:186)

Assim como Arruda, João Fragoso analisa a importância do mercado interno para os estudos de economia colonial. Ele demonstra como esse mercado é também espaço para as acumulações endógenas e para a criação de uma autonomia colonial frente às flutuações econômicas externas. Ele demonstra o quanto é importante a existência de uma rede mercantil para a economia colonial, analisando resultados e contribuições de trabalhos como os de Rae Floury e de Stuart Schwartz, os quais estudam o caso específico da Bahia. A partir deles, Fragoso enfatiza o papel desempenhado por comerciantes no financiamento de atividades agrícolas e de instituições religiosas:

"Dessa forma, a presença de um mercado interno e de produções coloniais a ele ligadas não é um privilégio do Rio de Janeiro da época da crise do sistema colonial (passagem do século XVIII para o XIX). Parece, portanto, que tais produções e o mercado interno são antigos traços da economia colonial", (grifo meu). (Fragoso, 1992:24)

Apesar de não citar exemplos para um período anterior ao final do século XVII, Fragoso destaca que tais produções voltadas para o mercado interno parecem ser traços antigos da economia colonial. Não existem muitos exemplos para isso, mas a produção para abastecimento no início do século XVII, mesmo para regiões distantes de sua produção, é registrada nos trabalhos de Caio Prado Júnior e Alice Canabrava, como nos lembra Ilana Blaj, em sua tese de doutorado (1995:80) ${ }^{10}$. Trata-se aqui da produção de farinha de trigo na região paulista comercializada em Santos e na região do Prata".

${ }^{10}$ Cf.: Prado Jr., Caio. Evolução Política do Brasil e Outros Estudos. São Paulo: Braziliense, 1975; e Canabrava, Alice. O Comércio Português no Rio Prata (1580-1640). Belo Horizonte: Itatiaia, 1984.

"Alice Canabrava chega a mencionar, além do trigo, feijão, marmelada, couros, carne salgada que eram enviadas para o norte do Rio de Janeiro, Bahia e Santos. Apud: Blaj (1995:80). 
Para Blaj, é possível verificar a partir de 1690, a comercialização de "toda uma produção local que garantia um determinado nível de acumulação de capitais, justificando todo um comércio de gêneros de outras regiões e até de produtos importados" (1995:87). Outro fator considerado importante pela Autora é o fato de todas as operações mercantis serem feitas tendo o valor-dinheiro como referencial, o que a impedia de ser considerada como "mera subsistência". A partir dessas considerações, Ilana Blaj conclui que São Paulo, desde meados do século XVII, já estava integrada a uma economia de mercado e, por isso, não poderia ser considerada como uma área voltada apenas para o consumo local (Blaj, 1995:91-5). Em outro estudo, Blaj (1998) enfatizará que essa tendência, iniciada no século XVII, será reforçada pela economia do ouro no século XVIII.

Anterior ao trabalho de Ilana, o estudo de John Manuel Monteiro (1994:99) já ressaltava a importância de uma agricultura comercial de trigo que interligava a economia do Planalto com o litoral desde o início do século XVII. Para este Autor, o rápido crescimento da economia açucareira fez surgir no início do seiscentos, em zonas secundárias, oportunidades para os produtores de gêneros de abastecimento agrícolas e pecuários. Os mercados consumidores eram compostos pelos engenhos de cana-de-açúcar e pelos portos marítimos que estimularam os agricultores de São Paulo, sul da Bahia, Espírito Santo e Maranhão a produzir especificamente para "este incipiente circuito comercial intercapitanias".

Além dessa rede mercantil, Monteiro diz que, no âmbito mais estritamente local, já havia um esforço por parte das autoridades régias em estruturar uma economia integrada de mineração e agricultura para as capitanias do sul já em fins do século XVI, sendo o objetivo principal a transformação de São Paulo no "Celeiro do Brasil" (Monteiro, 1994:102). O principal produto produzido por São Paulo, nesse período, foi o trigo para abastecer os mercados litorais e não os mercados locais, que eram supridos por feijão, mandioca e milho. A produção de trigo destinava-se a abastecer a população "européia das vilas e cidades do litoral e às frotas portuguesas" no Rio, Bahia, Pernambuco e, até mesmo, em Angola.

Para esta rede mercantil, no entanto, podem ser consideradas, segundo dados do Autor, algumas características específicas, tais como: acesso ampliado às terras e à mão-de-obra indígena, financiamento proveniente dos bens dos órfãos, precariedade de transportes (que dependiam, para o seu baixo custo, de um aumento crescente de mão- 
de-obra indígena) e uma baixa rentabilidade nos negócios. Tudo isso explicaria, segundo Monteiro, a rápida ascensão e declínio da produção comercial de trigo em São Paulo. "De fato, apesar de alguns produtores e comerciantes terem conseguido enriquecer-se com os excedentes gerados pelo trabalho indígena, quase nenhuma fortuna colonial duradoura foi adquirida por este meio" (Monteiro, 1994:127).

Uma situação semelhante a esta foi analisada por Fragoso (1995) em relação ao Rio de Janeiro. Enfocando um período bem anterior, mais precisamente o início do século XVII, Fragoso encontra no Rio de Janeiro uma economia que se reproduz fora do mercado. Os fatores de produção: terra, trabalho, e capital não são mercantihzados. Esses fatores são adquiridos fora do mercado, através da concessão de sesmarias, do apresamento de índios e da concessão de créditos através de "instituições" da República como o "fundo dos órfãos". Fragoso percebe através de seu estudo que o processo de acumulação da elite se dava basicamente através do endividamento. Ao mesmo tempo em que essa elite se sobrepunha, por ter acesso privilegiado aos fatores de produção, ela se endividava em função de estar inserida numa economia com baixa taxa de acumulação e uma precária liquidez.

Fragoso afirma que o privilégio de ocupar cargos da República e de ter acesso a recursos públicos permitia, por via política, e não via mercado, a constituição de mecanismos diferenciados de acumulação em uma economia em formação. Essa relação, no entanto, comprometia essa elite agrária, pois, ao precisar recorrer ao mercado para adquirir a mão-de-obra africana, tornava-se dependente do capital mercantil. "Este fenômeno representa, portanto, uma redução da taxa de acumulação senhorial e, mais do que isto, pode significar um endividamento crônico daquela aristocracia, frente ao capital mercantil" (Fragoso, 1995:60). Não havia um mercado de fatores de produção, por isso não existia a possibilidade de acumulação via mercado. Apesar do Autor não se referir às produções voltadas para o mercado interno, parece-nos improvável - pelas mesmas razões apontadas acima que essa atividade pudesse ser geradora de acumulação mercantil naquele momento.

Ao analisar a economia fluminense a partir de escrituras públicas, entre as décadas de 1650 a 1750 , Antônio Carlos Jucá de Sampaio (2000) conclui que, somente a partir de fins do século XVII, os negócios agrários foram ultrapassados pelos negócios urbanos. Na- 
quele momento já existia uma elite mercantil constituída, que, por sua vez, não investia no setor açucareiro exportador e, sim, em propriedade produtoras de alimentos. Essa elite passou a comandar o sistema agrário da Capitania fluminense. A atividade que iria dinamizar essa produção de alimentos voltados para abastecimento interno seria, segundo Sampaio, a mineração.

Ilana Blaj (1998), ao estudar o processo de sedimentação das elites mercantis de São Paulo no século XVIII, procura detectar analises que demonstram a dinamização da economia paulista através do comércio interno nesse período. Ao contrário dos trabalhos tradicionais, que apontavam São Paulo como despovoada e decadente ao longo do século XVIII, seu estudo demonstra a existência de uma atividade comercial e de abastecimento que remontava ao final do século XVII. Ilana Blaj diz que essas pesquisas apontam para tendências que iriam se desenvolver de forma plena a partir da descoberta dos minérios nas áreas de Minas Gerais e Cuiabá.

"O que queremos enfatizar é que, através da articulação com os territórios metalíferos, acentua-se toda uma dinâmica já observada desde as últimas décadas do século XVII, qual seja, a crescente concentração, nas mãos da elite paulistana, de uma produção para o abastecimento interno, da criação de gado e das atividades mercantis mais rentáveis". (Blaj, 1998:289)

De acordo com os estudos aqui abordados, podemos perceber que, independentemente de haver uma produção interna que abastecia o mercado colonial, a dinamização dessa atividade, com a criação de articulações inter-regionais e o estabelecimento de uma elite mercantil a partir da renda dessa produção, só iria acontecer entre o final do século XVII e o início do século XVIII, principalmente devido ao impulso dado pelas regiões mineradoras. As principais razões apontadas para essa mudança foram: o aumento da mercantilização das produções, com a intensificação da utilização da mão-de-obra escrava africana; o processo de expansão e interiorização territorial; e o aumento da concentração populacional. Tudo isso possibilitou tornar a atividade de abastecimento mais rentável, vantajosa e relativamente especializada.

É interessante notar que essa é uma característica comum nas demais economias latino-americanas. Em todos os estudos analisados, encontramos a referência à mineração como impulsionadora de 
mercados internos antes da fragmentação da América Espanhola ${ }^{12}$. Segundo Peter Bakewell (1999), o início da extração mineral desencadeou o crescimento de regiões inóspitas, onde populações viviam de forma esparsa e primitiva.

"As estradas e o comércio expandiram-se rapidamente à medida que se desenvolveram novos circuitos econômicos, energizados pela mineração. Roupas, vinho e ferro da Espanha, escravos da África, sedas e especiarias do Oriente fluíam para as vilas mineiras; e para pagar por tudo isso, enormes quantidades de metal precioso, principalmente a prata, começaram a fluir na direção oposta. Todavia, nem todo o comércio era externo. A mineração também estimulou o desenvolvimento interno: o cultivo dos grãos no Bjío e em Michoacán, a produção de vinho na costa peruana e no Chile, a criação de gado bovino e de mulas nas províncias do Rio de La Plata, têxteis no Peru e em Quito; e em toda parte transportes e o trabalho especializado. Pouquíssimas regiões de grande porte escaparam à influência dos fluxos dos metais preciosos. A natureza, sob a forma da orogênese terciária, havia proporcionado a ampla dispersão da riqueza mineral que deu origem a esses fluxos". (Bakewell, 1999: 102)

José R. Amaral Lapa (1996) diz que, embora a América Portuguesa guarde grandes diferenças com relação à América Espanhola, é possível estabelecer uma comparação entre essas duas áreas de desenvolvimento colonial. A semelhança entre as duas pode ser percebida pela constituição de mercados internos vinculados às áreas de mineração.

"Em todo caso, em ambas as economias verifica-se nas Américas Hispânica e Portuguesa a vinculação comercial da população entregue à mineração com setores outros de áreas absorvidas pecuária de corte e de transporte, na produção têxtil, mesmo que

Sobre essa temática ver: MurdoJ. Macleod. Aspectos da economia interna da América espanhola colonial: mão-de-obra; tributação; distribuição e troca. In: Leslie Bethel História da América Latina, v. 2. São Paulo: Edusp, 1999; Assadourian, Carlos S. El Sistema de la Economia Colonial: Mercado interno, regiones y espado económico. Lima: Instituto de Estudios Peruanos, 1982; Florescano, Enrique (cord.). Haciendas, Latifundois y Plantationes en America Latina. México: Siglo XXI, 1978; Palomeque, Sílvia. Loja en el mercado interno colonial. Hisla,n.l, Peru, 1983... 
em escala doméstica e é claro na subsistência de pequenos produtores. É o que nos mostram essas performances, se não certo grau de autonomia e desenvolvimento interno e de integração regional, que se constrói contínua e significativamente sob o ponto de vista econômico e social, não deixando de ter certo alcance e atuação políticas". (Lapa, 1996:166)

Embora não tenhamos pesquisas desenvolvidas nesta área que nos permitam avançar nesta aproximação, pode-se dizer, a partir da literatura analisada, que é pertinente pensarmos nas semelhanças na formação dos espaços econômicos internos. No caso da América Portuguesa, na qual observamos o mercado interno colonial como uma formação mais consistente no início do século XVIII, percebemos os mesmos elementos apontados para o estudo da América Espanhola. Esses elementos que caracterizam os mercados coloniais da América Ibérica são: a mineração, o adensamento demográfico, a interiorização da agricultura e da pecuária, a formação de redes comerciais - transporte e comercialização - regulares, a especialização e diversificação da produção, a circulação, ainda que precária, de moedas e do ouro e prata como equivalente de troca.

Analisando a América Portuguesa, observamos que a produção de alimentos para o abastecimento interno sempre existiu em sua economia, com uma comercialização local e fora do local de produção. Mesmo assim, essa produção foi tradicionalmente tratada como "ancilar", "dependente", "secundária" em relação à produção dominante agroexportadora. É claro que a comercialização de produtos de abastecimento dependeria do surgimento de um mercado consumidor que fizesse valer a pena os investimentos na produção e em transporte dos bens produzidos. Como vimos no caso do trigo, apesar de haver essa demanda, os negócios não foram suficientemente rentáveis para garantir sua manutenção, ainda mais quando a mão-deobra e o transporte passaram a implicar custos. Por isso, quando se fala em desenvolvimento "relativamente autônomo" na Colônia, fala-se em formação do mercado interno ou visibilidade do mercado interno a partir do século XVIII. Foi a partir desse momento que se delinearia não só um comércio de longa distância, mas se ressaltariam a ligação inter-regional e o início do processo de formação de um mercado capaz de gerar riquezas e investimentos em produção interna, inclusive para a compra da mão-de-obra necessária.

Retornando ao estudo de Luiz Felipe de Alencastro (2000), podemos 
recolocar essa questão. Ele descreve que, em determinados períodos de escassez e fome causados por guerra ou desequilíbrio entre a produção de alimentos e a produção para exportação, havia sempre a oferta de produtos regionais, "limitada em volume, mas variada em mercadoria" (Alencastro, 2000: 361-3). Entretanto, essa produção de abastecimento não caracterizava esse mercado como "interno", o que irá acontecer somente a partir do final do século XVII.

"No final do século XVII o Brasil formado a partir de Angola estava prontinho. O mercado atlântico impusera o primado do tráfico negreiro, interpretado pela Igreja como uma obra de caridade cristã e de evangelização. O escravismo dominava tudo, a barreira indígena no interior fora destroçada, o território se repovoava dentro do esquadro colonial, o gado se expandia, os mestiços e mulatos furavam o seu lugar. Nas décadas seguintes, a economia do ouro instaura uma divisão inter-regional do trabalho na América portuguesa, engendra um só mercado e faz isso tudo virar uma coisa só". (Alencastro, 2000:353)

Alencastro, entretanto, alerta que esse mercado interno que emerge no século XVIII, de certa maneira, oculta o seu apêndice angolano e as relações comerciais bilaterais que prosseguem entre a Bahia e a Costa da Mina. Assim, a aparente coesão territorial encobre a "desterritorialização do mercado de trabalho escravo", que se tornará novamente evidente no século XIX (Alencastro, 2000: 353).

Mesmo após o estabelecimento de redes mercantis, não havia uma interligação regional muito ampla. Fragoso (1992: 86) descreve o comércio marítimo do Rio de Janeiro no final do século XVIII abastecido, fundamentalmente, pela região sul-sudeste. Acrescenta, que, de acordo com estudos de Larissa Brown ${ }^{13}$, havia três distintas redes mercantis nos grandes portos agroexportadores — Rio de Janeiro, Salvador e Recife - as quais não mantinham relações muito intensas. As razões para essa fraca integração podiam estar relacionadas, além dos problemas de transporte interno, aos fortes monopólios comerciais estabelecidos principalmente no Rio de Janeiro e na Bahia.

Em 1794, numa carta do Príncipe Regente endereçada ao ViceRei do Brasil, podemos observar claramente esse conflito:

${ }^{13}$ Larissa Brown, "Internal Commerce in a Colonial Economy: Rio de Janeiro and its Hinterland, 1790-1822", Tese de Doutoramento, 1986. Apud Fragoso (1992:86). 
"(...) chegou um requerimento de alguns negociantes da cidade da Bahia, expondo os inconvenientes que experimentam de terem ultimamente obrigadas algumas das embarcações que mandavam ao Rio Grande (carregar de gêneros daquele país) de fazerem escala no seu regresso pelo porto do Rio de Janeiro. E fazendo muito digno da Real atenção de sua Alteza o dito requerimento, pela utilidade pública de que resulta da facilidade, da liberdade que se deve conceder ao comércio interior: É o mesmo senhor servido ordenar que os gêneros e produções de qualquer das capitanias do Brasil possam ser transportadas de umas para as outras, sem o menor obstáculo, ou restrição, e sem obrigação nenhuma de escalas por esse, ou aquele porto: O que Vossa Excelência fará executar nessa capitania, e o participará ao Governador do Rio Grande de São Pedro para que assim o fique entendendo, dando conta por essa Secretaria de Estado da exata observância desta real determin ação ${ }^{1{ }^{14}}$.

O interesse em manter os canais de comunicação entre as capitanias do Brasil, por parte do Príncipe Regente, certamente abalava os interesses comerciais dos grandes negociantes do Rio de Janeiro, inclusive doVice-Rei, o Conde de Resende, que se havia envolvido, no ano de 1792, em uma disputa com o Juiz de Fora, Baltazar da Silva Lisboa, o qual o acusava de obrigar navios de mantimentos a descarregar no Rio de Janeiro, para, conjuntamente com atravessadores, estocar as mercadorias e as revender em Santa Catarina e Rio São Francisco. A questão foi resolvida pelo Ministro Melo e Castro favoravelmente ao Conde de Resende, que alegou tratar-se de uma provisão para o armazém público que havia construído para o bem geral ${ }^{15}$. Quando em 1794 se proibiu as interferências do Rio de Janeiro sobre as embarcações destinadas aos outros portos do Brasil, o Conde de Resende se antecipa, mas não deixa de cobrar uma taxa de "direitos" sobre tais embarcações.

"Em carta de 13 de março do referido ano n. 1 V.E. conta da providência que dera para que os navios que saem da capitania

Arquivo Histórico Ultramarino, documentação referente ao Rio de Janeiro, Caixa 157 doc 57.

${ }^{15}$ Ver: Arquivo Histórico Ultramarino, documentos referentes ao Rio de Janeiro,

Caixa 152, docs, 57 e 63; caixa 153, doc. 21 ; caixa 154, doc. 53; caixa 155, doc. 13.

90 | Cláudia Maria das Graças Chaves 
do Rio Grande não sejam obrigados a entrar no Rio de Janeiro; providência esta muito acertada, e com a qual V.E. antecipou a execução das ordens de S.A que lhe participei em carta do $1^{\circ}$ de junho de 1794 para que a navegação entre as diferentes capitanias do Brasil fosse inteiramente livre da obrigação de escalas. Ao que acrescentarei agora as ordens de S.A que não só os navios que saírem do porto do Rio Grande podem navegar em direitura para os outros portos do Brasil, mas não deverão pagar no Rio de Janeiro direito algum das fazendas e gêneros que transportarem, ficando por conseqüência desnecessárias as medidas que V.E. tomou para a arrecadação desses direitos, que ficam abolidos. (...) Luís pinto de Souza" (10 de fevereiro de 1795).

A localização do centro administrativo e de dois portos ${ }^{17}$ impor-

${ }^{16}$ Arquivo Histórico Ultramarino, documentos referentes ao Rio de Janeiro, Caixa 158, doc. 20 .

${ }^{17}$ O porto de Santos também funcionava como um catalisador do comércio de cabotagem entre as capitanias da região Centro-Sul. Assim como no porto do Rio de Janeiro, havia queixas sobre a obrigatoriedade de se passar em suas "alfândegas". Em uma representação endereçada ao Conselho Ultramarino, negociantes daVila de Paranaguá se queixam de serem obrigados a parar no porto de Santos quando se dirigem ao Rio de Janeiro: "Dizem Antônio dos Santos Amara, João Gonçalves dos Santos, Manoel Antônio Pereira de Lima e Manoel Gonçalves Guimarães que eles suplicantes conservam casa de negócio naVila de Paranaguá, na de Curitiba e na cidade do Rio de Janeiro, porém desse giro se vêem os suplicantes prejudicialmente embaraçados porque o Ilmo. Exmo. General daquela capitania de São Paulo com o zelo do bem público e comum daqueles povos tem ordenado que todas as embarcações que saírem carregadas de Paranaguá para o Rio de Janeiro, primeiro vão com escala para o porto da Vila de Santos para venderem os efeitos aqueles moradores para depois seguirem para o Rio de Janeiro: porém aos suplicantes é isto muito prejudicial, porque além de não poderem desviar parte alguma daqueles efeitos que as duas casas de negócios, de Curitiba e de Paranaguá mandam para o Rio de Janeiro para desta ir a fazenda da precisa e ficam os efeitos diminutos acresce que chega a embarcação dos suplicantes à Vila de Santos tomando a barra com risco, e os moradores entram a prometer preços diminutos pelos mantimentos e mais efeitos que, às vezes, não chegam a salvar os gastos, e não fazendo conta, vende-se por tão ínfimos preços querendo-se navegar a embarcação para o Rio de Janeiro, o Dr.Juiz de Fora daquela Vila não consente de sorte que a embarcação não há de se demorar ou os ditos efeitos hão de ser vendidos com prejuízo dos suplicantes e de todos os que vão à dita Vila por serem obrigados e não por conta própria. (...) nesta atenção esperam os suplicantes que V. M. Usando de suas preciosas qualidades com que nosso feliz reinado tem tranqüilizado seus fieis vassalos haja por bem mandar que a embarcação dos suplicantes e seus efeitos da sua negociação não sejam obrigados a retroceder com escala no 
tantes deram a região Centro-Sul uma relação comercial mais estreita entre suas capitanias, tornando-se menos freqüente essa mesma relação com as regiões Norte e Nordeste. No caso de Minas Gerais, cujo comércio só poderia ser feito por via terrestre ou fluvial, esse contato se restringiu ao sul da Bahia, mesmo assim, muito menos intenso, se comparado ao Rio ou São Paulo.

Vejamos, portanto, como se inicia esse processo em Minas Gerais. A grande maioria dos autores que analisam o processo de colonização das áreas mineradoras, baseando-se fortemente em relatos de época, enfatizam a necessidade de produção de alimentos para uma expressiva população que se deslocou para a região. Assim, Minas se abasteceria através do sul da Bahia, com alimentos e gados; de São Paulo, por onde passavam não só alimentos, mas também animais de carga — as famosas feiras de muares de Sorocaba; do Rio de Janeiro, de onde vinham, sobretudo, alimentos e outros produtos importados. ${ }^{18}$ Essas áreas, por sua vez, estavam interligadas a outras regiões do Nordeste e do Sul, pois constituíam importantes áreas urbanizadas no CentroSul, sobretudo a cidade do Rio de Janeiro, que centralizava as atividades de importação e exportação. O Rio de Janeiro tornou-se importante centro econômico - entreposto comercial - e centro político administrativo com a transferência da sede administrativa colonial em 1763. As Minas, por sua vez, rapidamente deixaram de ser abastecidas por produções de outras capitanias, passando a produzir grande parte dos produtos de abastecimento alimentar ali consumidos.'

Na segunda metade do século XVIII, a capitania mineira não só se tornou auto-suficiente em produtos alimentares, como também passou a exportar sua produção para as capitanias mais próximas, inclusive funcionando como entreposto comercial para Goiás e Mato Grosso. É importante frisar que não coube apenas à mais famosa de suas comarcas, a do Rio das Mortes, produzir alimentos para o mercado interno. Em minha dissertação de mestrado, analisei a produção

Porto de Santos antes sim em direitura ao Rio de Janeiro lugar de seu destino e navegação (...)" da Câmara de Paranaguá. Abril de 1795. Arquivo Histórico Ultramarino, documentação do Rio de Janeiro, caixa 158, doe 57.

${ }^{18}$ Ver principalmente Zemella (1990), Ellis (1958) e Boxer (1969).

${ }^{19}$ O importante estudo de Guimarães e Reis (1987) demonstra que a produção de alimentos, desde o início do processo de colonização das regiões mineradoras, faz-se junto às lavras de mineração, não tendo sentido pensar em constantes crises de fome na região por se tratar de terras impróprias para o cultivo, ou por roubar mão-deobra à mineração. 
e o comércio de alimentos e manufaturados nas comarcas do Serro Frio e do Rio das Velhas, observando as importantes redes comerciais estabelecidas e que não se restringiam a mercados locais ou vicinais.

$O$ fato de a capitania mineira não apresentar as principais características de uma economia escravista colonial - do tipo plantations, tais como, a existência de agroexportação e de uma produção voltada para o mercado internacional ${ }^{20}$ - não possibilita estender as características de seu mercado interno à colônia como um todo, mas propicia a compreensão da posterior integração de Minas Gerais ao contexto do Império como região economicamente importante. Desta maneira, cabe "repensar" a discussão sobre mercado interno na América Portuguesa e, para isso, tentei situar a produção historiográfica sobre o tema. Minha maior preocupação, como demonstrei ao longo daquele texto, foi abordar a construção do mercado interno ao final do século XVIII e início do século XIX. Entretanto, é preciso pensar o espaço territorial com o qual estamos trabalhando. Em primeiro lugar, este período não é representativo de todo o período colonial, muito menos no que diz respeito a formação de um mercado interno. Por isso, torna-se importante avaliar os fundamentos de interpretações opostas, que orajulgam o mercado interno uma formação impossível dentro de uma economia colonial e que ora consideram o mercado como inerente à formação das sociedades. Note-se que a palavra em destaque é "mercado", e não "comércio" ou "trocas".

A noção de mercado interno está associada à idéia de mercados minimamente integrados num plano regional ou até nacional. Não se trata ainda de uma "nação-mercado" — isto é, do rompimento de todas as barreiras internas com a formação de um mercado nacional integrado. No caso do mercado interno na América Portuguesa, observamos importantes traços de integração, mas que ainda estavam profundamente marcados pela política de fragmentação colonialista, na qual se incentivava a correspondência direta das Capitanias com a metrópole e não a integração delas. Sem dúvida, os estudos sobre a formação e a consolidação das elites mercantis no período colonial têm colaborado para compreendê-1o enquanto uma formação histórica específica.

Foi exatamente no sentido de pensar o mercado como uma formação histórica específica, e não como categoria analítica, que

\footnotetext{
Cf. Fragoso (1992:16).
} 
podemos utilizar para demonstrar maior ou menor eficiência econômica, que abrimos essa discussão sobre a restrição conceituai e os parâmetros de economias capitalistas comumente utilizados. É necessário, portanto, demonstrar que o mercado não é um agente organizador da ordem social; ele é o resultado dela. Ele não é um ator, mas uma construção que, como bem demonstra Thompson, tanto pode ser real como pode ser uma metáfora. Neste caso, "quando visto sob esse aspecto, o mercado é uma máscara usada por interesses particulares que não coincidem com os da 'nação' ou da'comunidade', mas que querem, acima de tudo, ser confundidos com esses interesses coletivos". (Thompson, 1998:235)

No caso da economia colonial, não podemos esquecer a existência da profunda hierarquização dessa sociedade, a permanência de um Estado monárquico, o regime de trabalho escravista, a predominância de uma economia agrária, e um sistema social extremamente excludente. Entretanto, o discurso que se impõe no Império LusoBrasileiro ao final do século XVIII é o das liberdades irrestritas de mercado que repara todos os males, sem se considerar as limitações sociais e políticos que envolviam a Colônia. O contexto em que o discurso da economia política ganha relevo nas práticas mercantis e nas decisões políticas e econômicas do "reformismo ilustrado" é parte da cultura econômica que se construiujunto com o mercado.

\section{Bibliografia}

Alencastro, Luiz Felipe. O Trato dos Viventcs: Formação do Brasil no Atlântico Sul. São Paulo: Cia. das Letras, 2000.

Arte e Diccionario do Commercio e Economia Portugueza. Lisboa: Officina Domingos Gonçalves, 1784. (Seção de reservados da Biblioteca Nacional em Lisboa)

Arruda, José Jobson de A. O Brasil no Comércio Colonial. São Paulo: Ática,1980.

A produção econômica. In: Silva, M. Beatriz N.O Império Luso-Brasileiro 1750-1822. Lisboa: Estampa, 1986.

Bakewell, Peter. A mineração na América espanhola colonial. In: BETHELL, Leslie. América Latina Colonial, v. II. São Paulo: Edusp, 1999.

Blaj, Ilana. Agricultores e comerciantes em São Paulo nos inícios do século XVIII: o processo de sedimentação da elite paulistana. Revista Brasileira de História, v. 18, n. 36, p. 281-296.1998.

A Trama das Tensões: o processo de mercantilização de São Paulo colonial. São Paulo: USP, 1995. (Tese, doutorado em História Social).

Boxer, Charles R. A Idade do Ouro no Brasil. São Paulo: Nacional, 1969 
Caldeira, Jorge. A Nação Mercantilista. São Paulo: Editora 34, 1999.

Cardoso, Ciro Flamarion S. Agricultura, Escravidão e Capitalismo. Petrópolis:Vozes, 1979.

Ellis, Myrian. Contribuição ao estudo do abastecimento das zonas mineradoras do Brasil no século XVIII. Revista de História, v. 17, n. 36, out/dez, 1958.

Fragoso, João Luís R. Homens de Grossa Aventura: Acumulação e Hierarquia na Praça Mercantil do Rio de Janeiro (1790-1830). Rio de Janeiro: Arquivo Nacional, 1992.

\& Florentino, Manolo. O Arcaísmo como Projeto: Mercado Atlântico, Sociedade Agrária e Elite Mercantil no Rio de Janeiro. Rio de Janeiro: Diadorim, 1993.

Furtado, Celso. Formação Econômica do Brasil. São Paulo: Nacional, 1974.

Gorender, Jacob. O Escravismo Colonial. São Paulo: Ática, 1978. A Escravidão Reabilitada. São Paulo:Ática, 1990.

Goulart, José A. Tropas e Tropeiros na Formação do Brasil. Rio de Janeiro: Conquista, 1961. Guimarães, Carlos M. \& Reis, Liana M.Agricultura e caminhos de Minas (1700-1750). Revista do Departamento de História. Belo Horizonte: UFMG, n. 4,1987.

Holanda, Sérgio B. A mineração: antecedentes luso-brasileiros. In: História Geral da Civilização Brasileira: A Época colonial. São Paulo: Difel, t. 1, v. 2, 1977.

Caminhos c Fronteiras. Rio de Janeiro: José Olympio, 1957.

Lapa, José do A. Estrutura interior. In: Szmrecsányi,Tamás. História Econômica do Período Colonial. São Paulo: Hucitec, 1996.

Linhares, Maria Yedda L. História do Abastecimento; uma Problemática em Questão (15301918). Brasília: Binagri, 1979.

.A pecuária e a produção de alimentos na colônia. In: Szmrecsányi,Tamás. História Econômica do Período Colonial. São Paulo:Hucitec, 1996.

\& SILVA, Francisco C.T. História da Agricultura Brasileira. São Paulo: Brasiliense, 1981 .

Monteiro, Jonh Manuel. Os Negros da Terra. São Paulo: Companhia das Letras, 1994.

Polányi, Karl. A Grande Transformação: as origens da nossa época. Rio de Janeiro: Campus, 2000 .

Prado Jr., Caio. História Econômica do Brasil. São Paulo: Brasiliense, 1978.

Simonsen, Roberto. História Econômica do Brasil São Paulo: Cia. Editora Nacional, 1957.

Sampaio, Antônio Carlos Jucá de. Hierarquização Social e Estratégias de Classe: a produção da exclusão na Capitania do Rio de Janeiro. 1650-1750. Niterói: UFF, 1999.

Schwartz, Stuart. Perspectives of brazilian peasantry: a review essay. Peasant Studies, v. 5, n. 4,1976 .

Thompson, Eduard P. Tradición, Revuelta y Conciencia de Clase. Barcelona: Critica, 1989.

Economia moral revisitada. In: Costumes em Comum. Estudos sobre a cultura popular tradicional. São Paulo: Cia das Letras, 1998.

Zemella, Mafalda P. O Abastecimento da Capitania das Minas Gerais no Século XVIII. São Paulo: Hucitec/Edusp, 1990. 